\title{
ANAESTHETIC MANAGEMENT OF A PATIENT WITH HOMOCYSTINURIA
}

\author{
Dr. Vandana Gogate ${ }^{1}$, Dr. Kusha Nag ${ }^{2}$, Dr. Kedareshwar ${ }^{3}$, Dr. C. S. Sanikop ${ }^{4}$, Dr. Naveen Singh ${ }^{5}$. \\ Associate Prof. Dept of Anaesthesiology, Post Graduate student, Dept of Anaesthesiology ${ }^{2}$, Assistant \\ Prof. Dept of Anaesthesiology, Prof and Head, Dept of Anaesthesiology ${ }^{4}$, Post Graduate student, \\ Dept of Anaesthesiology ${ }^{5}$ \\ Jawaharlal Nehru Medical College, Belgaum, Karnataka, India.
}

*Corresponding author : abhijitgogate@hotmail.com

\begin{abstract}
Key words: homocystinuria, thromboembolism, hypoglycemia, general anaesthesia, homocysteine metabolism.
\end{abstract}

\begin{abstract}
Homocystinuria is an autosomal recessive disease with multiple systemic involvement. Extracapsular extraction of lens is the most commonly performed elective ocular procedure for homocystinuric children. These children present with particular anaesthetic concerns during surgery. Here we report a case of a 14 year old boy with homocystinuria posted for extracapsular lens extraction under general anaesthesia. Precautions were taken perioperatively to prevent the various complications associated with this condition for a favourable perioperative outcome.
\end{abstract}

Homocystinuria is an autosomal recessive metabolic disorder of sulfur amino acid metabolism. It occurs due to deficiency or absence of the enzyme cystathionine-beta-synthase which converts dietary methionine to cystathionine leading to accumulation of homocysteine in plasma and urine. This evokes a high cardiovascular risk and a very high incidence of thromboembolic complications leading to increased mortality. ${ }^{1}$

The hypercoagulable state and subsequent anticoagulation therapy, creates a unique anaesthetic challenge that must be carefully managed.

Here we present the anaesthetic management and perioperative implications of a case of homocystinuria.

\section{Case report}

A 14 year old male child presented with the complaint of diminished vision in both eyes and was posted for extracapsular extraction of the lens in the right eye. Child was a known case of homocystinuria and was on treatment with pyridoxine and folic acid. His developmental history revealed delayed achievement of milestones. He had developed cortical vein thrombosis 6 months back and was on warfarin, which was stopped one month ago.

On examination, his weight was $25 \mathrm{~kg}$. Eye examination revealed bilateral anterior subluxation of lens. Systemic examination was normal.

Routine haematological, biochemical and coagulation profile were normal. Chest X-ray, ECG and echocardiography were also normal.

On the day of surgery, pyridoxine, folic acid, and Vitamin $\mathrm{B}_{12}$, was given in the morning and the patient was allowed to take water till four hours before surgery. An intravenous infusion of 5\% dextrose was started to prevent hypoglycaemia and ensure adequate hydration. Glycopyrrolate $0.1 \mathrm{mg}$, 
midazolam $1.5 \mathrm{mg}$ fentanyl $40 \mathrm{mcg}$ were given intravenously as premedication.

In the operation theatre, routine monitors were attached and basal vital parameters were noted. Induction of anaesthesia was with thiopentone sodium $125 \mathrm{mg}$ and vecuronium $2.5 \mathrm{mg}$ i.v. He was intubated with an appropriately sized ETT. Anaesthesia was maintained with oxygen, air, sevoflurane (4\%) and vecuronium; nitrous oxide was avoided.

Intravenous fluids were given at a rate of 1.5 times the calculated rate to ensure adequate hydration and prevent thromboembolism. Legs were massaged to prevent thromboembolism. Patient was reversed with glycopyrrolate $0.2 \mathrm{mg}$ and neostigmine $1.25 \mathrm{mg}$ and extubated. The vital parameters and glucose levels were monitored and remained stable throughout the perioperative period.

Postoperatively intravenous infusion of $5 \%$ dextrose was continued.

Diclofenac $25 \mathrm{mg}$ i.m was given for postoperative analgesia.

The preoperative drug therapy was continued.

He was discharged on $3^{\text {rd }}$ postoperative day with improvement in vision.

\section{Discussion}

Homocystinuria is an inherited autosomal recessive disease ${ }^{1}$ with an incidence of about

1 in 100,000 to 1 in 200,000 live births. It is a multi systemic disorder of the connective tissues, muscles, central nervous system and cardiovascular system.

Plasma levels of homocysteine are controlled by two distinct metabolic pathways (Figure 1) Homocysteine is diverted to the trans-sulfuration pathway when methionine concentrations exceed the capacity of the methionine cycle. Cystathionine beta-synthase (CBS) and vitamin $\mathrm{B} 6$ are required for trans-sulfuration.

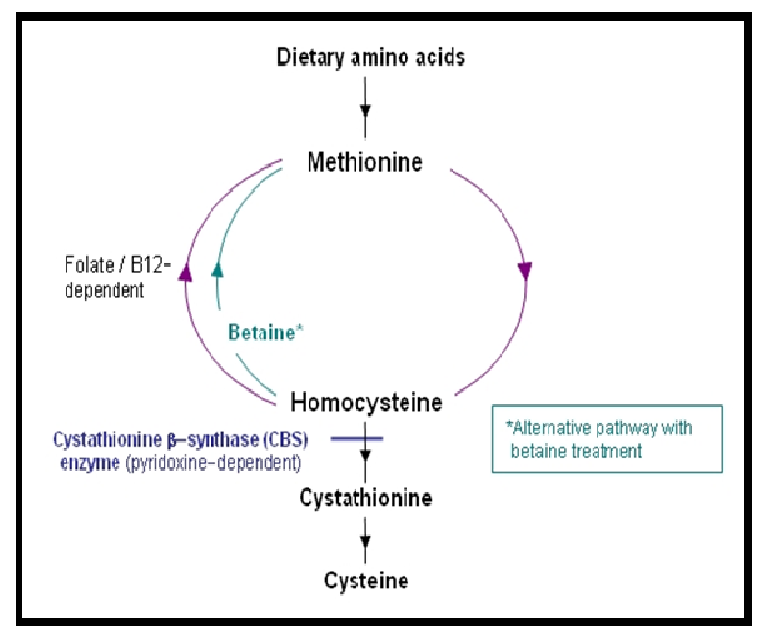

Figure 1 :

Homocysteine metabolism pathway.

The accumulation of homocysteine and its metabolites is caused by a deficiency of CBS and has a genetic predisposition.

Clinical features are

- $\quad$ Pale and pink skin,

- Malar rashes,

- $\quad$ Fine fragile hair,

- Marfanoid habitus,

- $\quad$ Pes excavatum, genu valgum, kyphoscoliosis

- $\quad$ Subluxation of lens.

Ectopia lentis occurs in at least $90 \%$ of these patients, necessitating surgical correction. Thromboembolic complications of the central nervous system, and psychomotor delay may occur during the first year of life. Approximately $60 \%$ of patients are mentally retarded. ${ }^{2}$ There may be symptoms including muscle weakness due to an insult to pyramidal motor tract neurons.

\section{Major anaesthetic concerns}

\section{Risk of thromboembolism}

This is the most notable and life-threatening complication. Mild or moderate hyperhomocysteinemia is an independent risk factor for venous thrombosis as well as atherosclerosis. $^{3}$ Sequelae include heart failure, cerebrovascular accident, myocardial infarction, and renal infarction. ${ }^{4}$

These patients may have a perioperative mortality rate as high as 50\%. Elevated 
concentration of homocysteine irritates the vascular intima promoting thrombotic nidus formation and increasing platelet aggregation. ${ }^{5}$ Dehydration or stress in the perioperative period may precipitate these episodes.

Measures to prevent perioperative thromboembolic events ${ }^{6}$

- Low protein, low methionine diet.

- Administration of low dose aspirin.

- Adequate hydration.

- Avoid hypotensive states.

- Pneumatic stockings or massaging of legs to prevent stagnation of blood.

- Early ambulation.

2. Use of nitrous oxide :

Nitrous oxide causes increase in the homocysteine levels by inhibiting methionine synthase and is associated with postoperative myocardial ischaemia. ${ }^{7}$

Foschi et $\mathrm{al}^{8}$ indicated that total homocysteine could decrease in patients in whom the general anahetic regimen was free of nitrous oxide.

Hence, we avoided nitrous oxide.

\section{Hypoglycemia :}

Hypoglycaemia is due to methionine induced increase in insulin release. ${ }^{9}$

Measures to prevent perioperative hypoglycemia:

- Short fasting period.

- Close monitoring of perioperative blood glucose.

- Perioperative intravenous dextrose infusion.

\section{Patient Positioning :}

These patients may have severe osteoporosis and hence must be carefully positioned.

\section{Conclusion}

Careful consideration of pathophysiology, judicious preparation and right anaesthetic measures help to prevent or reduce the hazards of general anaesthesia associated with homocystinuria.

\section{References}

1. Crooke JW, Towers JF, Taylor WH: Management of patients with homocystinuria requiring surgery under general anaesthesia. Brit J Anaesth 43:9699, 1971.

2. Ozand PT, Devol EB, Gascon GG: Neurometabolic diseases at a national referred centre. Five years experience at the King Faisal Specialist Hospital and Research Centre. J Child Neurol 7 (suppl):4-11, 1992.

3. Falcon CR, Cattaneo M: High prevalence of hyperhomocysteinemia in patients with venous thrombosis. Arterioscler Thromb 14:1080, 1994.

4. Mudd SH, Skovby F, Levy HL, Pettigrew KD, Wilcken B, Pyeritz RE, Andria G, Boers GH, Bromberg IL, Cerone R: The natural history of homocystinuria due to cystathionine Beta synthase deficiency. Am Hum Genet 37:1-31, 1985.

5. Harker LA, Ross R, Slichter SJ, Scott CR: Homocystine-induced arteriosclerosis. The role of endothelial cell injury and platelet response in its genesis. J Clin Invest 58:731-741, 1976.

6. Yun-Hui Teng, Chun-Sung Sung, Wen-Wei Liao, Sheng-Chin Kao. General Anaesthesia for Patient with Homocystinuria - A Case Report Acta anaesthesiol sin 40:153-156, 2002.

7. Badner NH, Beattie WS, Freeman D, Spence JD. Nitrous oxide-induced increased homocysteine concentrations are associated with increased postoperative myocardial ischemia in patients undergoing carotid endarterectomy. Anesth Analg 2000; 91 : 1073-79.

8. Foschi D, Rizzi A, Zighetti ML, Bissi M, Corsi F, Trabucchi E, Mezzetti M, Cattaneo M. Effects of surgical stress and nitrous oxide anaesthesia on peri operative plasma levels of total homocysteine. Anaesthesia 2001; 56: 670-89.

9. Lowe S, Johnson DA, Tobias JD: Anaesthetic implications of the child with homocystinuria. J Clin Anesth 6:142-144, 1994. 